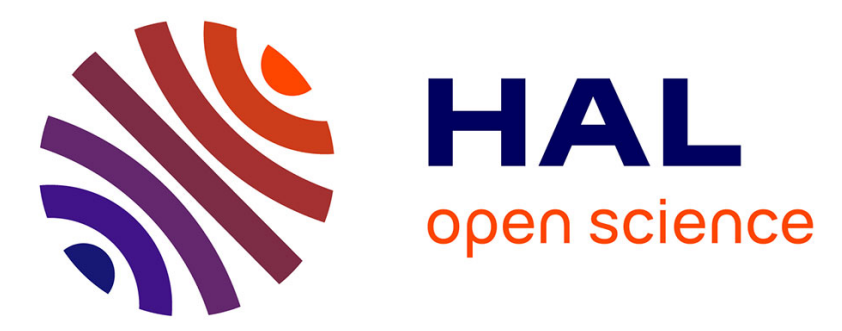

\title{
Latest view on the mechanism of action of deep brain stimulation.
}

Constance Hammond, Rachida Ammari, Bernard Bioulac, Liliana Garcia

\section{To cite this version:}

Constance Hammond, Rachida Ammari, Bernard Bioulac, Liliana Garcia. Latest view on the mechanism of action of deep brain stimulation.. Movement Disorders, 2008, 23 (15), pp.2111-21. $10.1002 /$ mds. 22120 . inserm-02950812

\section{HAL Id: inserm-02950812 https://www.hal.inserm.fr/inserm-02950812}

Submitted on 28 Sep 2020

HAL is a multi-disciplinary open access archive for the deposit and dissemination of scientific research documents, whether they are published or not. The documents may come from teaching and research institutions in France or abroad, or from public or private research centers.
L'archive ouverte pluridisciplinaire HAL, est destinée au dépôt et à la diffusion de documents scientifiques de niveau recherche, publiés ou non, émanant des établissements d'enseignement et de recherche français ou étrangers, des laboratoires publics ou privés. 


\section{Latest view on the mechanism of action of DBS}

\begin{tabular}{|c|c|}
\hline Journal: & Movement Disorders \\
\hline Manuscript ID: & MDS-08-0001 \\
\hline Wiley - Manuscript type: & Review \\
\hline $\begin{array}{r}\text { Date Submitted by the } \\
\text { Author: }\end{array}$ & 02-Jan-2008 \\
\hline Complete List of Authors: & $\begin{array}{l}\text { Hammond, Constance; INSERM, INMED Inserm } \\
\text { Ammari, Rachida; Inserm, INMED Inserm } \\
\text { Bioulac, Bernard; CNRS, UMR5227 } \\
\text { Garcia, Liliana; CNRS, UMR5227 }\end{array}$ \\
\hline Keywords: & DBS, electrophysiology, Parkinson, dystonia, OCD \\
\hline
\end{tabular}

\section{(5) ScholarONE \\ Manuscript Central}




\section{Latest view on the mechanism of action of deep brain stimulation}

Constance Hammond ${ }^{1}$, Rachida Ammari ${ }^{1,2}$, Bernard Bioulac ${ }^{2}$ and Liliana Garcia ${ }^{2}$

${ }^{1}$ Institut de Neurobiologie de la Méditerranée (INMED), Unité mixte Inserm-Université Aix Marseille II, 163 route de Luminy, BP13, 13273 Marseille Cédex 9, France.

${ }^{2}$ UMR 5227 CNRS-Université Bordeaux 2, 146 rue Léo Saignat, 33076 Bordeaux Cédex, France.

\section{Corresponding author:}

Constance Hammond, INMED Inserm, 163 route de Luminy, BP13, 13273 Marseille Cédex 9, France. Tel: 334918281 10, fax: 33491828101

email: hammond@inmed.univ-mrs.fr

Running title: Mechanisms of DBS

Key words: DBS, electrophysiology, antidromic spikes, Parkinson, Dystonia, OCD

Word count: title (65 letters \& spaces), abstract (138 words), 


\begin{abstract}
How does DBS alleviate symptoms of neurological disorders? Do the effects of DBS stem solely or even largely from local effects on the stimulated brain structure or are they also mediated by distal actions of DBS? Indeed, DBS as an extracellular stimulation is expected to preferentially activate axons leading to antidromic activation of local and afferent neurons. Antidromic spikes collide with ongoing spontaneous ones that propagate in the reverse (orthodromic) direction. Consequently, DBS decreases spontaneous pathological patterns. From their point of activation, DBS-evoked axonal spikes also propagate in the orthodromic direction but how synapses transmit DBS-driven patterns over the long term remains to be determined. Therefore, the best site of implantation of the DBS electrode may be in a region where the DBS-driven activity spreads to most of the identified, dysrhythmic, neuronal populations without causing additional side effects.
\end{abstract}




\section{Introduction}

Deep brain stimulation (DBS) has the potential to provide substantial benefit for various neurologic and neuropsychiatric diseases. DBS is an intracerebral, extracellular stimulation consisting of short pulses (in the order of $100 \mu \mathrm{s}$ ) regularly applied at a frequency of at least $100 \mathrm{~Hz}$ over a period of several years. First tested in ventral thalamic nuclei to alleviate essential tremor ${ }^{1}$, it is now widely used in the internal pallidal segment (GPi) or subthalamic nucleus (STN) for Parkinson's disease ${ }^{2-4}$, in the GPi for generalized dystonia ${ }^{5,6}$, and more recently for other diseases such as treatment-resistant obsessive compulsive disorder $(\mathrm{OCD})^{7,8}$, Tourette syndrome $\mathrm{e}^{9,10}$ and depression ${ }^{11}$. Sites of stimulation are located inside the cortico-basal ganglia-thalamo-cortical loops, in motor or limbic regions, depending on the clinical signs.

Two major explanations have been proposed for the mechanism of action of DBS: (1) it silences stimulated neurons (i.e., it is equivalent to a local lesion) or (2) It introduces a new activity in the network. The first theory is based on the assumption that a group of neurons is responsible for the pathological activity of the whole network. Therefore silencing these neurons will immediately suppress the pathological activity. The second explanation leads to a different hypothesis: The whole network malfunctions for complex reasons but the injection in one point of a DBS-driven activity that propagates and consequently attenuates the pathological activity in many nuclei, may be beneficial as long as it does not activate too many undesirable regions. The clarification of the mechanisms of action of DBS is imperative to avoid implanting electrodes in regions having a low impact on clinical signs and/or leading to incapacitating side effects. In this review, we focus on results obtained within the last four years from multiunit and single cell electrophysiological recordings. 


\section{MECHANISMS OF STN-DBS IN THE CASE OF PARKINSON'S DISEASE}

Increased synchronization and the appearance of oscillations in the activity patterns of populations of STN and GP neurons but also in motor cortical networks are salient aspects of Parkinsonism (PD). Pathological synchronization has been observed in human PD patients ${ }^{12}$, 1-methyl-4-phenyl-1,2,3,6-tetrahydropyridine (MPTP)-treated monkeys ${ }^{13}$ and rodents with 6hydroxydopamine (6-OHDA) lesions ${ }^{14}$, suggesting functional alterations in the basal ganglia network. In particular increased coherence in the beta-band $(13-30 \mathrm{~Hz})$ is correlated with severity of symptoms in humans ${ }^{15-17}$.

Mechanisms of STN-DBS have long been reduced to a lesion-like or inhibition hypothesis until in 2003 , Hashimoto et $\mathrm{al}^{18}$ and ourselves ${ }^{19}$ from data obtained in two totally different preparations (MPTP-treated monkeys and slices from reserpine-treated rats, respectively) introduced the concept that high frequency stimulation drives neuronal activity in a pattern locked to the stimulation frequency or its sub harmonics and consequently erases pathological activity. This DBS-driven pattern could show alternated periods of activity and pauses and was observed only when stimulation parameters were clinically efficient ${ }^{18}$ or close to the clinical ones ${ }^{20}$. On the light of studies performed during the late four years we will see whether this hypothesis is still valid and how it can be generalized.

The striatal network, the extrastriatal network and the place of the STN

Two networks can be distinguished within the basal ganglia, the striatal and the extrastriatal networks (Fig. 1). The striatal network lies in a single nucleus in rodents (the striatum), or in two nuclei in primates (caudate and putamen). It consists of GABAergic and cholinergic interneurons and GABAergic projection neurons. In contrast, the extrastriatal network is made up by five different neuronal populations, scattered in five different nuclei, the globus pallidus (external and internal), the subthalamic nucleus (STN) and the substantia nigra pars reticulata $(\mathrm{SNr})$ and compacta $(\mathrm{SNc})$. The link between the striatal and extrastriatal 
networks is made by the projection neurons of the striatum, the GABAergic medium spiny neurons and in the reverse direction by the dopaminergic neurons of the SNc. The large reduction of the latter, due to the degeneration of nigro-striatal neurons, and the consequent loss of dopamine in the striatum, leads to 'typical' PD.

STN occupies a strategic position inside the extrastriatal network as STN neurons are the only glutamatergic neurons, they receive afferents from motor-related cortical areas, they project to all nuclei of the extrastriatal network including SNc dopaminergic neurons and are reciprocally connected with brainstem neurons of the pedunculopontine nucleus (PPN) ${ }^{21}$.

\section{Preparations and parameters of stimulation used to study STN-DBS are diverse}

Different types of preparations have been used to study DBS mechanisms, from anesthetized in vivo models of PD to in vitro slices. Each preparation has its own advantages and pitfalls but their combination should allow understanding DBS mechanisms as long as we keep aware of the limitations of the technique used. In the present review DBS refers to high frequency stimulations in vivo and HFS to that in vitro.

The question of the mechanisms of action of DBS relies on the analysis of what does a high frequency and long duration stimulation of neuronal elements (DBS is applied for years). Electrophysiologists are used to study synaptic potentials or currents in response to single stimulations but here the question is far more complex mainly for technical reasons as recordings have to be maintained for minutes or hours and spikes identified among artifacts. If all studies on DBS mechanisms test high frequency $(100-180 \mathrm{~Hz})$ stimuli, they rarely apply them for long durations. Considering synaptic plasticity (potentiation or depression) that usually occurs in synaptic transmission after tetanic stimulation ${ }^{22}$, ultrashort (ms, s) and long (days, years) duration stimulations should evoke very different responses. Therefore, to evaluate the electrophysiological effects of STN-DBS, a compromise would be to stimulate and record for at least 30-60 minutes. To compare results from different studies, intensity of 
stimulation is not as informative as current density $\left(\mathrm{mA} / \mathrm{cm}^{2}\right)$. This parameter depends on the diameter of the stimulation electrode or contact and is not always available from papers. For this reason we never mention here the value of current intensity or density.

\section{Is STN-DBS noxious to STN neurons?}

Before analyzing the electrophysiological effect of STN-DBS, the first point to verify is the extent of STN lesion due to the chronic presence of the DBS electrode and stimulation. The classical Medtronic electrode was implanted in one STN in control or MPTP-treated monkeys, and the stimulation continuously applied for 7 months (pulses at $130 \mathrm{~Hz}, 60 \mu \mathrm{s}$ duration). Cell counts performed in Nissl-stained coronal sections of the STN showed that the STN having the implant had only $5 \%$ difference in total cell number compared to the side that did not have the implant ${ }^{23}$. Therefore, the chronically-implanted DBS electrode does not induce local degenerescence and the beneficial effects of STN-DBS are not mediated by a lesion of the STN.

\section{Does STN-DBS lock the electrophysiological activity of STN neurons to harmonics of the stimulation frequency?}

Studies of the effect of STN-DBS locally on STN neurons gave the most controversial data. This probably results from the difficulty to separate the very short latency evoked spikes from the stimulation artifacts or as we will see later on the difference between cell body and axonal activity in some conditions. Benazzouz group recorded inhibition of STN neurons during STN-DBS in 6-OH DA rats ${ }^{24}$ but recently described that this inhibition only lasted 4 ms after each stimulus when the interval between two stimuli was fixed at $7.7 \mathrm{~ms}(130 \mathrm{~Hz})^{25}$. In patients, STN-DBS of short durations decreased STN neurons activity ${ }^{26}$ and changed the firing pattern of some STN neurons via a non-identified mechanism ${ }^{27}$. 
In slices STN activity is very low compared to that in vivo and does not show the pathological alterations resulting from dopamine depletion probably because the basal ganglia network is absent in coronal slices. Slices have however the advantage of allowing intracellular recordings and precise analysis of the correspondence between spikes and stimuli. In our experiments, all STN spontaneous spikes disappeared during STN-HFS and were replaced by spikes evoked by and locked to stimuli (Fig. 2A). The STN firing pattern under HFS consisted of trains of evoked spikes in the gamma range frequency that totally erased spontaneous STN activity ${ }^{19,20}$. Interestingly, the fixed latency of DBS-driven spikes (close to $0 \mathrm{~ms}$ ), the presence of the initial segment-somatodendritic (IS-SD) break in the recordings (Fig. 2A right) and the lack of effect of blockers of synaptic transmission, all strongly suggested that HFS-evoked spikes were antidromic (antidromic spikes propagate toward cell bodies i.e. in the direction opposite to physiological spikes that propagate in the orthodromic direction toward axon terminals). STN-DBS thus preferentially activated STN efferent axons probably at the level of their initial segment or first Ranvier node. Evoked antidromically propagated to STN somas where they were recorded (Fig. 1A, inset STN). Antidromic spikes by colliding with orthodromic, spontaneous ones erased STN spontaneous activity.

One possible explanation for the controversial results obtained in vivo and in vitro is that action potentials evoked in axons by local DBS, inefficiently invade cell bodies in the antidromic direction due to geometric ratio. DBS would therefore lead to active axons and silent somas ${ }^{28,29}$. Since extracellular microelectrode recordings are biased toward recording action potentials from cell bodies rather than axons, this would result in the appearance of decreased activity within the stimulated structure though efferent axons are excited (see discussion $\mathrm{in}^{30}$ ). In contrast intracellular or juxtacellular recordings record axonal spikes 
evoked at the level of the initial segment (IS spikes, Fig. 2A middle) and higher intensities of stimulation would compensate for the geometric ratio.

\section{Does STN-DBS antidromically activate afferent neurons to the STN?}

A DBS electrode in a nucleus not only activates the efferent axons of local neurons but also the afferent axons. STN-DBS thus evokes antidromic spikes in neurons of the motor cortex and GP (Fig. 1). Axons passing through or near the STN can also be activated. Due to the low probability of antidromic invasion of somas, antidromic spikes are usually evoked in a subset of afferent neurons only.

So, a subset of layer V/VI neurons of motor cortex, that project to $\mathrm{STN}^{31}$ displayed antidromic spikes (latency around $2 \mathrm{~ms}$ ) whose frequency decreased with time to a steady state at around $40 \mathrm{~Hz}$ in response to $120 \mathrm{~Hz}$ STN stimulation ${ }^{32}$ (Fig. 2B). Recordings of short latency evoked potentials over the motor cortex during STN-DBS also indicated that axons were most likely activated ${ }^{33}$. As glutamatergic cortico-subthalamic neurons give off many axon collaterals in deep and superficial layers ${ }^{34}$ that contact other projection neurons and local GABAergic interneurons, antidromic invasion of a subset of neurons may retrogradely affect cortical circuits in complex ways (Fig. 1 inset cortex). But antidromic excitation of cortical networks may not be very efficient. For example, whereas the fast conducting branches in the highly myelinated brainstem region follow high frequency stimulation, the slower conducting fibres in the poorly myelinated thalamic region fail to transmit consecutive antidromic spikes and maintain a steady low-frequency $(6-12 \mathrm{~Hz})$ spike output during the stimulation ${ }^{29}$.

STN-HFS in slices $(130 \mathrm{~Hz}, 90 \mu \mathrm{s})$ evoked antidromic spikes in GPe neurons with a mean latency of around $2 \mathrm{~ms}$ (Fig. 2C) that erased the ongoing activity in the recorded neurons. This may have consequences on neighbouring GPe neurons if the antidromic spikes propagate in the complex network of local GABAergic collaterals that synapse onto other GP neurons $^{35}$ (Fig. 1 inset GP). 
STN-DBS also activates axons passing through and near the STN. Thus short STNDBS $(130 \mathrm{~Hz}, 60 \mu \mathrm{s}, 30 \mathrm{~s}$ trains) in control rats in vivo antidromically activated a subpopulation of $\mathrm{SNr}$ neurons with a latency of around $1 \mathrm{~ms}^{36}$, probably as a result of the activation of ascending $\mathrm{SNr}$ axons. This decreased the spontaneous activity of the antidromically activated $\mathrm{SNr}$ neurons and inhibited other $\mathrm{SNr}$ neurons as shown in recordings ${ }^{36}$ probably via the activation of the complex network of intranigral collaterals between GABAergic $\mathrm{SNr}$ cells ${ }^{37}$. The same experiment has not been performed for SNc neurons.

In conclusion, STN-DBS antidromically activates subsets of neurons in the different nuclei that send axons to or close to the stimulated site. In that context, STN-DBS probably also antidromically activates PPN neurons that project to STN, though short trains of stimulation have only been tested at present ${ }^{38,39}$. Once evoked, antidromic axonal spikes propagate to their corresponding cell bodies at the stimulation frequency or its sub harmonics, may also propagate in recurrent axonal collaterals and activate synaptic transmission that impinges onto other projection neurons (GP, SNr) or local interneurons (see Fig.1, insets cortex and GPe). The overall result on a network is difficult to guess as it needs to know the probability of propagation of antidromic spikes in axonal branches and how these spikes evoke synaptic responses at a long term.

\section{Does STN-DBS orthodromically induce a complex locking of GP and SNr neuronal activity?}

From their point of initiation, axonal spikes also propagate in the orthodromic direction toward axon terminals, i.e. along STN efferent axons (Fig. 1). Do these spikes evoke postsynaptic responses? STN-DBS parameters that improved spontaneous movements and muscle tone $(130,210 \mu \mathrm{s}, 25 \mathrm{~s}-5 \mathrm{~min})$ in MPTP-treated monkeys, evoked stimulus-locked double excitatory responses at latencies around 4 and $6 \mathrm{~ms}$ in the globus pallidus (GPe and GPi $)^{18}$ (Fig. 3A). It thus shifted the firing pattern of GPe and GPi neurons, from irregular to 
stimulus-synchronized and regular. The most probable mechanism is the orthodromic activation of STN efferent axons projecting to GP, the release of glutamate and the monosynaptic excitation of postsynaptic GPe or GPi neurons. In contrast, in control monkeys, bursts of $100 \mathrm{~Hz}$ stimuli (10 pulses) induced powerful excitatory responses in the GPe but inhibition in the GPi attributed to the activation of the disynaptic STN-GPe-GPi pathway ${ }^{40}$.

Do GPi-DBS and STN-DBS have similar effects on GPi neurons since both ameliorate clinical signs of $\mathrm{PD}^{41}$ ? Bar-Gad et $\mathrm{al}^{42}$ recorded the activity of GPe or GPi neurons in MPTPtreated monkeys in response to microstimulations applied in GPe or GPi $(135 \mathrm{~Hz}, 200 \mu \mathrm{s}$, 600-3000 trains of 10 stimuli separated by $500 \mathrm{~ms}$ ). They report in both GP a double excitation with latencies of 3 and $6 \mathrm{~ms}$, separated by a short period of inhibition. Overall $70 \%$ of the neurons displayed locked activity i.e. they lost their basic firing pattern and switched to a predicted, orderly discharge that was locked to the stimulus. Again, a complex locking of target neurons activity is recorded.

Does STN-DBS similarly affect GP and SNr neurons? Deniau's group studied the spontaneous and evoked SNr activity before and during STN-DBS in control rats or rats treated with neuroleptics to block dopaminergic transmission. In control rats, STN-DBS (130 $\mathrm{Hz}, 60 \mu \mathrm{s}, 30 \mathrm{~s}$ ) evoked antidromic spikes and inhibition as previously seen but also orthodromic spikes (excitation) in $\mathrm{SNr}^{36}$. The short latency excitation is likely to result from the orthodromic activation of the excitatory $\mathrm{STN}-\mathrm{SNr}$ glutamatergic axon terminals. In cataleptic rats, at parameters that reversed the catalepsy $(130 \mathrm{~Hz}, 60-80 \mu \mathrm{s})$, STN-DBS regularized the pattern of discharge of STN neurons as it significantly decreased the number of neurons exhibiting burst discharges and reduced the number of bursts emitted by bursting neurons. It also reversed to control the classical triphasic response to motor cortex stimulation $^{43}$. Intracellular recordings from neurons in the pars compacta of the $\mathrm{SN}$ (SNc) 
during short duration STN-DBS in slices revealed increased generation of EPSPs and increased frequency of action potentials ${ }^{44}$.

In PD patients under surgical procedure, at parameters $(130 \mathrm{~Hz}, 60 \mu \mathrm{s})$ that induce clinical improvement of rigidity and finger tapping, STN-DBS increased mean spike frequency of $\mathrm{SNr}$ neurons and evoked short latency $(4 \mathrm{~ms})$ excitatory responses. Autocorrelograms demonstrated the presence of a periodic spiking at $130 \mathrm{~Hz}$. In parallel the firing pattern changed from irregular to a 'grouped' pattern consisting of groups of spikes separated by longer periods of pauses ${ }^{45}$. In another study STN-DBS $(140 \mathrm{~Hz}, 60 \mu \mathrm{s})$ evoked in $\mathrm{SNr}$ neurons a three phase sequence, inhibition (0-2 ms) - excitation (2-4 ms) - inhibition (4-7 ms) after the stimulation pulse. There was a $51 \%$ decrease in the percentage of the spikes contributing to bursts and a $70 \%$ decrease in the mean duration of bursting mode activity ${ }^{46}$.

Therefore, STN-DBS eliminates in some GP and SNr neurons the 'pathological' information encoded by the basal ganglia during PD and replaces it by a stimulus-driven firing pattern that is likely to contribute to the clinical motor improvements. This new activity would result, at least in part, from the activation of STN efferent fibres. The multiphasic pattern of the responses (alternated periods of excitation and inhibition) led some authors to suggest a participation of polysynaptic activity. This has to be confirmed since high frequency stimulations usually suppress polysynaptic responses. The exact mechanism of the complex responses recorded during short term STN-DBS or GP-DBS is not yet elucidated.

\section{Does STN-DBS act on the survival and dopamine metabolism of remaining SNc neurons?}

The rationale for testing the effect of STN-DBS on SNc neurons survival is the non tested hypothesis that glutamatergic inputs to SNc neurons, namely those from the $\mathrm{STN}^{47,48}$ and $\mathrm{PPN}^{38,49}$ would be excitotoxic to $\mathrm{SNc}$ dopaminergic neurons that have not yet degenerated, since both inputs are overactive in PD. The question then arised on whether STN-DBS protects remaining dopaminergic neurons from degeneration. This has been 
investigated in murine and primate models of PD. Temel et $\mathrm{al}^{50}$ injected 6-OHDA at four sites in both striatum of rats. During the phase of ongoing neurodegeneration in the SNc, half of the lesioned rats were treated with bilateral STN-DBS (pulse width at $60 \mu \mathrm{s}$, frequency at 130 $\mathrm{Hz}, 1 \mathrm{~h}$ per day over a period of three months). This amount of STN modulation was sufficient to obtain a significant rescue of SNc dopaminergic neurons from cell death. Bilateral STN-DBS not only had a protective effect on the number of TH positive neurons but also on the total number of neurons in the SNc. It could be argued that this effect resulted from a non identical retrograde degeneration of $\mathrm{SNc}$ dopaminergic neurons in the different lesioned rats and thus did not result from STN-DBS. For this reason, to mimic the clinical situation and to be able to observe neuroprotection, Benabid's group performed a subacute model of MPTP treatment in primates and induced a symmetrical 50\% reduction of Nisslstained and TH positive cells in the two SNc. They applied a unilateral STN-DBS after MPTP treatment and compared the number of Nissl-stained and TH-positive SNc cells between each side of the brain in two animals, the non DBS side serving as a control. They found around $20 \%$ more dopaminergic neurons in the SNc of the side that underwent DBS, compared to the non-DBS side. When the DBS electrode was located outside the STN, the difference between both sides was not significant ${ }^{23}$. Therefore STN-DBS may have offered neuroprotection to nigral dopaminergic neurons that would have degenerated as part of the disease process.

Several studies reported an excellent clinical outcome of STN-DBS in L-dopa responsive forms of Parkinson's disease and STN-DBS allows the discontinuation of L-Dopa or equivalent treatment or large reductions in daily dose ${ }^{51}$ in contrast to GPi-DBS. The question therefore aroused whether STN-DBS favours dopamine release in the striatum. Savasta's group tested this hypothesis by measuring the extracellular content of dopamine and its metabolites in the striatum of rats that underwent a partial 6-OHDA lesion of one $\mathrm{SNc}^{52}$. After a delay of three weeks to allow the degeneration of $70 \%$ of dopaminergic nigrostriatal 
fibres in the dorsolateral part of the striatum, they implanted the stimulation electrode in the STN and the microdialysis probe in the striatum, both ipsilateral to the lesion. The i.p. injection of L-dopa $(50 \mathrm{mg} / \mathrm{kg})$ increased by around 3 times the content of extracellular dopamine in the lesioned striatum measured with HPLC one hour after the injection. STNDBS at clinical parameters $(130 \mathrm{~Hz}, 60 \mu \mathrm{s}$, during one hour) amplified by around $100 \%$ this L-dopa-induced increase of dopamine during the stimulation period and for the following 2.5 $\mathrm{h}$ after the end of stimulation. In contrast, in intact animals, L-dopa failed to enhance the extracellular dopamine levels during the stimulation period. This suggests that STN-DBS interacts in a synergistic manner with L-dopa. The underlying mechanisms have not been elucidated. The functional tone of the nigrostriatal DA system can be regulated at two sites, via inhibitory autoreceptors located on presynaptic dopaminergic terminals and controlling the synthesis or release of DA, and via receptors on the soma or dendrites of these neurones, involved in regulating impulse flow ${ }^{53}$. It seems plausible that STN-DBS has effects on the inputs coming from the STN to the somatodendritic receptors of SNc neurons. A simple explanation would be that STN-DBS acts by directly modulating the firing rate of dopaminergic neurones ${ }^{54}$. This, together with a decrease of inhibitory feedback regulation with the progression of nigrostriatal degeneration could stabilize the DA levels in the striatum in synergy with L-dopa.

\section{STN-DBS regularizes neuronal activity in the extrastriatal network as well as in the motor cortex and amplifies L-dopa treatment}

To conclude, STN-DBS due to the central position of the STN in the basal ganglia has multiple effects. It introduces a stimulation-locked, intermittent activity in many sites of the basal ganglia network (STN, motor cortex, GPe, GPi, SNr), mainly via antidromically propagated DBS-driven spikes and thus decreases ongoing pathological activity at these sites. This may also be valid for PPN and the good results obtained on axial motor signs with STN- 
DBS in association with $\mathrm{PPN}-\mathrm{DBS}^{55}$, may result from a better regularization of PPN discharge pattern. Direct activation of passing fibres dorsal to the STN and in particular nigrostriatal and pallido-thalamic axons may also participate to the beneficial effect as the best position of the DBS electrode active contact is in the dorsal part of the STN. Via a still unknown mechanism, STN-DBS protects dopaminergic neurons that have not yet degenerated and ameliorates the endogenous release of dopamine in the striatum when applied concomitantly with L-dopa treatment. This last hypothesis on dopamine release is strengthened by the fact that only patients responding to L-dopa are good candidates for STNDBS. Conversely, this may imply that STN is not a good target for DBS in the case of dopamine-independent disorders.

\section{DBS for other neurological disorders}

\section{DBS in motor cortico-basal ganglia-thalamocortical loop for essential tremor}

DBS of ventral nuclei of the thalamus can dramatically relieve essential tremor in the majority of patients ${ }^{1,56}$. Essential tremor is thought to arise from dysfunction of the glutamatergic olivocerebellar pathway which projects to ventral thalamic (VL) nuclei ${ }^{57}$. VL-HFS in rat brain slices silenced thalamic relay neurons after a transient period of intense depolarization ${ }^{58}$. The authors hypothesized that VL-HFS introduced a functional deafferentation of stimulated neurons, thereby stopping tremor from propagating to thalamo-cortical loops. To test whether this depression of afferent synaptic transmission is selective, they stimulated at $5 \mathrm{~Hz}$ in two different loci within the VL to mimic afferent stimuli at tremor frequency. Both stimulations evoked excitatory postsynaptic potentials (EPSPs) at $5 \mathrm{~Hz}$ in the recorded VL neuron. A concomitant short duration HFS $(125 \mathrm{~Hz}$, for $10 \mathrm{~s})$ in one locus only totally suppressed the 5 $\mathrm{Hz}$ EPSPs in the HFS-stimulated pathway but not in the non-stimulated one, suggesting that HFS selectively disrupts afferent synaptic transmission ${ }^{59}$. 


\section{DBS in motor cortico-basal ganglia-thalamocortical loop for dystonia}

Neuronal activity is altered in basal ganglia and ventral thalamic nuclei in dystonia ${ }^{60}$. The firing pattern of GPi neurons known to be regular in monkeys ${ }^{61}$ consists in patients of irregular grouped discharges with intermittent pauses and a third of the neurons discharge at the frequency of the electromyogram ${ }^{62,63}$. Neurons in ventral oralis posterior / intermediate nuclei of the thalamus (Vop/Vim) have a sustained activity at $130-150 \mathrm{~Hz}$, organized in bursts lasting from $500 \mathrm{~ms}$ to $5 \mathrm{~s}$ and recurring at a frequency similar to that of dystonia frequency ${ }^{62}$. DBS for medically intractable forms of dystonia has been tested in $\mathrm{GPi}^{64}, \mathrm{STN}^{65}$ and VL nuclei of the thalamus ${ }^{66}$. GPi-DBS is now currently used for primary generalized DYT-1 positive dystonia and idiopathic cervical dystonia ${ }^{6,67,68}$. In contrast to Parkinson's disease, the beneficial effects of DBS in dystonia are not immediate but progressive over weeks to months. However, recordings in patients can only be performed during the surgical procedure, i.e. at $\mathrm{t} 0$, or in control animals, owing to the lack of reliable animal models of dystonia.

During short duration GPi-DBS, 50 to $70 \%$ Vop neurons of the thalamus reduced their average discharge frequency with a delay of a few $\mathrm{ms}$ in control monkeys ${ }^{69}$ or dystonic patients $^{30}$, suggesting that DBS activates GPi efferent axons that are GABAergic and inhibitory onto thalamic neurons (Fig. 3B). Moreover, $88 \%$ of Vop neurons were antidromically activated with a $1 \mathrm{~ms}$ latency probably as a result of the activation of axons originating in Vop and passing in the vicinity of the GPi-DBS electrode (Fig. 2E).

\section{DBS in limbic cortico-basal ganglia-thalamocortical loop for obsessive compulsive disorder}

Obsessive compulsive disorder has been consistently associated with metabolic hyperactivity in the caudate nucleus, medial thalamus, and orbitofrontal cortex in patients at rest $^{70-72}$. Recently, a dramatic increase in neuronal activity of the ventral caudate nucleus was identified and correlated to the patients' self-evaluated obsessions ${ }^{73}$. DBS of the ventral anterior internal capsule ${ }^{74,75}$ or accumbens ${ }^{7}$ are therapeutic approaches for treatment-resistant 
OCD. DBS mechanisms were studied with imaging techniques in patients and electrophysiological techniques in control rats as robust animal models of OCD are lacking.

DBS of the accumbens $(130 \mathrm{~Hz}, 200 \mu \mathrm{s}$, during $30 \mathrm{~min}$ ) in control rats induced the inhibition of nearly all the recorded orbitofrontal neurons probably as a result of the antidromic activation of cortico-accumbens axons and other corticofugal axons ${ }^{76}$. The authors suggest that antidromic spikes propagate in axonal collaterals of cortical neurons and thus evoke inhibitory responses in neighbouring neurons via GABAergic interneurons (Fig. 1, inset cortex). But this has still to be demonstrated as antidromic axonal spikes often inefficiently invade axon collaterals and $\operatorname{somas}^{29}$.

\section{CONCLUSION}

Electrical stimulation of a nucleus with short duration pulses (less than $1 \mathrm{~ms}$ ) preferentially activates axons rather than somas ${ }^{77,78}$. This results in the generation of axonal spikes and antidromic activation of local cell bodies via their efferent axons as well as distant cell bodies that send axons to the stimulated structure (Fig. 1). DBS-driven antidromic spikes collide with spontaneous orthodromic ones leading to the blockade of ongoing (pathological) activity. This dual effect has been clearly shown in the $\mathrm{STN}^{19}$, motor cortex ${ }^{32}$, GPe-GPi (Ammari et al personal communication) and $\mathrm{SNr}^{36}$ during STN-DBS, in ventral neurons of the thalamus during GPi-DBS ${ }^{30}$ and suggested in the orbitofrontal cortex during accumbens$\mathrm{DBS}^{76}$. An additional complication stems from the fact that activated axons also propagate spikes in the orthodromic direction and give rise to sustained neurotransmitter release $\mathrm{e}^{79-81}$. How postsynaptic responses (glutamatergic or GABAergic) follow a high frequency and long duration stimulation such as DBS is a question that still remains open, as the electrophysiological studies performed so far have only focused on relatively short term stimulations $^{18,30,42,69}$. The overall consequence of DBS on stimulated networks appears to be 
the generation of a new activity, locked to the stimulation but with a lower frequency and interspersed pauses. This DBS-driven activity significantly attenuates the spontaneous pathological one, exacerbates the responsiveness to L-dopa and reverses several markers to $\operatorname{control}^{52,82,83}$, yet preserves the transmission of cortical information ${ }^{43,76}$.

\section{Acknowledgements}

This work was supported by Institut National de la Recherche Médicale (Inserm), Fondation de France and Association France Parkinson.

\section{REFERENCES}

1. Benabid AL, Pollak P, Gervason C, Hoffmann D, Gao DM, Hommel M et al. Long-term suppression of tremor by chronic stimulation of the ventral intermediate thalamic nucleus. Lancet 1991, 337(8738):403406.

2. Limousin P, Pollak P, Benazzouz A, Hoffmann D, Le Bas JF, Broussolle E et al. Effect of parkinsonian signs and symptoms of bilateral subthalamic nucleus stimulation. Lancet 1995, 345(8942):91-5.

3. Benabid AL, Deuschl G, Lang AE, Lyons KE, Rezai AR. Deep brain stimulation for Parkinson's disease. Mov Disord 2006, 21 Suppl 14:S168-S170.

4. Rezai AR, Kopell BH, Gross RE, Vitek JL, Sharan AD, Limousin P et al. Deep brain stimulation for Parkinson's disease: surgical issues. Mov Disord 2006, 21 Suppl 14:S197-S218.

5. Kumar R, Dagher A, Hutchison WD, Lang AE, Lozano AM. Globus pallidus deep brain stimulation for generalized dystonia: clinical and PET investigation. Neurology 1999, 53(4):871-874.

6. Coubes P, Cif L, El FH, Hemm S, Vayssiere N, Serrat S et al. Electrical stimulation of the globus pallidus internus in patients with primary generalized dystonia: long-term results. J Neurosurg 2004, 101(2):189194.

7. Aouizerate B, Cuny E, Martin-Guehl C, Guehl D, Amieva H, Benazzouz A et al. Deep brain stimulation of the ventral caudate nucleus in the treatment of obsessive-compulsive disorder and major depression. Case report. J Neurosurg 2004, 101(4):682-686.

8. Lipsman N, Neimat JS, Lozano AM. Deep brain stimulation for treatment-refractory obsessivecompulsive disorder: the search for a valid target. Neurosurgery 2007, 61(1):1-11. 
9. Houeto JL, Karachi C, Mallet L, Pillon B, Yelnik J, Mesnage V et al. Tourette's syndrome and deep brain stimulation. J Neurol Neurosurg Psychiatry 2005, 76(7):992-995.

10. Visser-Vandewalle V. DBS in tourette syndrome: rationale, current status and future prospects. Acta Neurochir Suppl 2007, 97(Pt 2):215-222.

11. Ressler KJ, Mayberg HS. Targeting abnormal neural circuits in mood and anxiety disorders: from the laboratory to the clinic. Nat Neurosci 2007, 10(9):1116-1124.

12. Priori A, Foffani G, Pesenti A, Tamma F, Bianchi AM, Pellegrini M et al. Rhythm-specific pharmacological modulation of subthalamic activity in Parkinson's disease. Exp Neurol 2004, 189(2):369379.

13. Raz A, Vaadia E, Bergman H. Firing patterns and correlations of spontaneous discharge of pallidal neurons in the normal and the tremulous 1-methyl-4-phenyl-1, 2,3,6- tetrahydropyridine vervet model of parkinsonism [In Process Citation]. J Neurosci 2000, 20(22):8559-71.

14. Sharott A, Magill PJ, Harnack D, Kupsch A, Meissner W, Brown P. Dopamine depletion increases the power and coherence of beta-oscillations in the cerebral cortex and subthalamic nucleus of the awake rat. Eur J Neurosci 2005, 21(5):1413-1422.

15. Gatev P, Darbin O, Wichmann T. Oscillations in the basal ganglia under normal conditions and in movement disorders. Mov Disord 2006, 21(10):1566-1577.

16. Uhlhaas PJ, Singer W. Neural synchrony in brain disorders: relevance for cognitive dysfunctions and pathophysiology. Neuron 2006, 52(1):155-168.

17. Hammond C, Bergman H, Brown P. Pathological synchronization in Parkinson's disease: networks, models and treatments. Trends Neurosci 2007, 30(7):357-364.

18. Hashimoto T, Elder CM, Okun MS, Patrick SK, Vitek JL. Stimulation of the subthalamic nucleus changes the firing pattern of pallidal neurons. J Neurosci 2003, 23(5):1916-1923.

19. Garcia L, Audin J, D'Alessandro G, Bioulac B, Hammond C. Dual effect of high-frequency stimulation on subthalamic neuron activity. J Neurosci 2003, 23(25):8743-8751.

20. Garcia L, D'Alessandro G, Fernagut PO, Bioulac B, Hammond C. The impact of high frequency stimulation parameters on the pattern of discharge of subthalamic neurons. J Neurophysiol 2005.

21. Bolam JP, Hanley JJ, Booth PA, Bevan MD. Synaptic organisation of the basal ganglia. J Anat 2000, 196(Pt 4):527-42. 
22. Luscher C, Nicoll RA, Malenka RC, Muller D. Synaptic plasticity and dynamic modulation of the postsynaptic membrane. Nat Neurosci 2000, 3(6):545-550.

23. Wallace BA, Ashkan K, Heise CE, Foote KD, Torres N, Mitrofanis J et al. Survival of midbrain dopaminergic cells after lesion or deep brain stimulation of the subthalamic nucleus in MPTP-treated monkeys. Brain 2007, 130(Pt 8):2129-2145.

24. Tai CH, Boraud T, Bezard E, Bioulac B, Gross C, Benazzouz A. Electrophysiological and metabolic evidence that high-frequency stimulation of the subthalamic nucleus bridles neuronal activity in the subthalamic nucleus and the substantia nigra reticulata. FASEB J 2003, 17(13):1820-1830.

25. Meissner W, Leblois A, Hansel D, Bioulac B, Gross CE, Benazzouz A et al. Subthalamic high frequency stimulation resets subthalamic firing and reduces abnormal oscillations. Brain 2005, 128(Pt 10):23722382.

26. Filali M, Hutchison WD, Palter VN, Lozano AM, Dostrovsky JO. Stimulation-induced inhibition of neuronal firing in human subthalamic nucleus. Exp Brain Res 2004, 156(3):274-281.

27. Welter ML, Houeto JL, Bonnet AM, Bejjani PB, Mesnage V, Dormont D et al. Effects of high-frequency stimulation on subthalamic neuronal activity in parkinsonian patients. Arch Neurol 2004, 61(1):89-96.

28. McIntyre CC, Grill WM, Sherman DL, Thakor NV. Cellular effects of deep brain stimulation: modelbased analysis of activation and inhibition. J Neurophysiol 2004, 91(4):1457-1469.

29. Chomiak T, Hu B. Axonal and somatic filtering of antidromically evoked cortical excitation by simulated deep brain stimulation in rat brain. J Physiol 2007, 579(Pt 2):403-412.

30. Montgomery EB, Jr. Effects of GPi stimulation on human thalamic neuronal activity. Clin Neurophysiol 2006, 117(12):2691-2702.

31. Canteras NS, Shammah-Lagnado SJ, Silva BA, Ricardo JA. Afferent connections of the subthalamic nucleus: a combined retrograde and anterograde horseradish peroxidase study in the rat. Brain Res 1990, $513(1): 43-59$

32. Li S, Arbuthnott GW, Jutras MJ, Goldberg JA, Jaeger D. Resonant antidromic cortical circuit activation as a consequence of high-frequency subthalamic deep-brain stimulation. J Neurophysiol 2007.

33. Baker KB, Montgomery EB, Jr., Rezai AR, Burgess R, Luders HO. Subthalamic nucleus deep brain stimulus evoked potentials: physiological and therapeutic implications. Mov Disord 2002, 17(5):969-983.

34. Cowan RL, Wilson CJ. Spontaneous firing patterns and axonal projections of single corticostriatal neurons in the rat medial agranular cortex. J Neurophysiol 1994, 71(1):17-32. 
35. Sadek AR, Magill PJ, Bolam JP. A single-cell analysis of intrinsic connectivity in the rat globus pallidus. J Neurosci 2007, 27(24):6352-6362.

36. Maurice N, Thierry AM, Glowinski J, Deniau JM. Spontaneous and evoked activity of substantia nigra pars reticulata neurons during high-frequency stimulation of the subthalamic nucleus. J Neurosci 2003, 23(30):9929-9936.

37. Mailly P, Charpier S, Menetrey A, Deniau JM. Three-dimensional organization of the recurrent axon collateral network of the substantia nigra pars reticulata neurons in the rat. J Neurosci 2003, 23(12):52475257.

38. Hammond C, Rouzaire-Dubois B, Féger J, Jackson A, Crossman AR. Anatomical and electrophysiological studies on the reciprocal projections between the subthalamic nucleus and nucleus tegmenti pedunculopontinus in the rat. Neuroscience 1983, 9(1):41-52.

39. Florio T, Scarnati E, Confalone G, Minchella D, Galati S, Stanzione P et al. High-frequency stimulation of the subthalamic nucleus modulates the activity of pedunculopontine neurons through direct activation of excitatory fibres as well as through indirect activation of inhibitory pallidal fibres in the rat. Eur J Neurosci 2007, 25(4):1174-1186.

40. Kita H, Tachibana Y, Nambu A, Chiken S. Balance of monosynaptic excitatory and disynaptic inhibitory responses of the globus pallidus induced after stimulation of the subthalamic nucleus in the monkey. $\mathbf{J}$ Neurosci 2005, 25(38):8611-8619.

41. Follett KA. Comparison of pallidal and subthalamic deep brain stimulation for the treatment of levodopainduced dyskinesias. Neurosurg Focus 2004, 17(1):E3.

42. Bar-Gad I, Elias S, Vaadia E, Bergman H. Complex locking rather than complete cessation of neuronal activity in the globus pallidus of a 1-methyl-4-phenyl-1,2,3,6-tetrahydropyridine-treated primate in response to pallidal microstimulation. J Neurosci 2004, 24(33):7410-7419.

43. Degos B, Deniau JM, Thierry AM, Glowinski J, Pezard L, Maurice N. Neuroleptic-induced catalepsy: electrophysiological mechanisms of functional recovery induced by high-frequency stimulation of the subthalamic nucleus. J Neurosci 2005, 25(33):7687-7696.

44. Lee KH, Chang SY, Roberts DW, Kim U. Neurotransmitter release from high-frequency stimulation of the subthalamic nucleus. J Neurosurg 2004, 101(3):511-517. 
45. Galati S, Mazzone P, Fedele E, Pisani A, Peppe A, Pierantozzi M et al. Biochemical and electrophysiological changes of substantia nigra pars reticulata driven by subthalamic stimulation in patients with Parkinson's disease. Eur J Neurosci 2006, 23(11):2923-2928.

46. Maltete D, Jodoin N, Karachi C, Houeto JL, Navarro S, Cornu P et al. Subthalamic stimulation and neuronal activity in the substantia nigra in Parkinson's disease. J Neurophysiol 2007, 97(6):4017-4022.

47. Hammond C, Deniau JM, Rizk A, Feger J. Electrophysiological demonstration of an excitatory subthalamonigral pathway in the rat. Brain Res 1978, 151(2):235-244.

48. Parent A, Hazrati LN. Functional anatomy of the basal ganglia. II. The place of subthalamic nucleus and external pallidum in basal ganglia circuitry. Brain Res Rev 1995, 20(1):128-154.

49. Charara A, Smith Y, Parent A. Glutamatergic inputs from the pedunculopontine nucleus to midbrain dopaminergic neurons in primates: Phaseolus vulgaris-leucoagglutinin anterograde labeling combined with postembedding glutamate and GABA immunohistochemistry. J Comp Neurol 1996, 364(2):254-266.

50. Temel Y, Visser-Vandewalle V, Kaplan S, Kozan R, Daemen MA, Blokland A et al. Protection of nigral cell death by bilateral subthalamic nucleus stimulation. Brain Res 2006, 1120(1):100-105.

51. Moro E, Scerrati M, Romito LM, Roselli R, Tonali P, Albanese A. Chronic subthalamic nucleus stimulation reduces medication requirements in Parkinson's disease. Neurology 1999, 53(1):85-90.

52. Lacombe E, Carcenac C, Boulet S, Feuerstein C, Bertrand A, Poupard A et al. High-frequency stimulation of the subthalamic nucleus prolongs the increase in striatal dopamine induced by acute 1-3,4dihydroxyphenylalanine in dopaminergic denervated rats. Eur J Neurosci 2007, 26(6):1670-1680.

53. Bunney BS, Aghajanian GK, Roth RH. Comparison of effects of L-dopa, amphetamine and apomorphine on firing rate of rat dopaminergic neurones. Nat New Biol 1973, 245(143):123-125.

54. Benazzouz A, Gao D, Ni Z, Benabid AL. High frequency stimulation of the STN influences the activity of dopamine neurons in the rat. Neuroreport 2000, 11(7):1593-1596.

55. Stefani A, Lozano AM, Peppe A, Stanzione P, Galati S, Tropepi D et al. Bilateral deep brain stimulation of the pedunculopontine and subthalamic nuclei in severe Parkinson's disease. Brain 2007.

56. Hariz MI, Krack P, Alesch F, Augustinsson LE, Bosch A, Ekberg R et al. Multicentre European study of thalamic stimulation for Parkinsonian tremor, a 6-year follow-up. J Neurol Neurosurg Psychiatry 2007.

57. Deuschl G, Bergman H. Pathophysiology of nonparkinsonian tremors. Mov Disord 2002, 17 Suppl 3:S41S48. 
58. Anderson T, Hu B, Pittman Q, Kiss ZH. Mechanisms of deep brain stimulation: an intracellular study in rat thalamus. J Physiol 2004, 559(Pt 1):301-313.

59. Anderson TR, Hu B, Iremonger K, Kiss ZH. Selective attenuation of afferent synaptic transmission as a mechanism of thalamic deep brain stimulation-induced tremor arrest. J Neurosci 2006, 26(3):841-850.

60. Lozano AM, Kumar R, Gross RE, Giladi N, Hutchison WD, Dostrovsky JO et al. Globus pallidus internus pallidotomy for generalized dystonia. Mov Disord 1997, 12(6):865-870.

61. Wichmann T, Bergman H, Starr PA, Subramanian T, Watts RL, DeLong MR. Comparison of MPTPinduced changes in spontaneous neuronal discharge in the internal pallidal segment and in the substantia nigra pars reticulata in primates. Exp Brain Res 1999, 125(4):397-409.

62. Zhuang P, Li Y, Hallett M. Neuronal activity in the basal ganglia and thalamus in patients with dystonia. Clin Neurophysiol 2004, 115(11):2542-2557.

63. Tang JK, Moro E, Mahant N, Hutchison WD, Lang AE, Lozano AM et al. Neuronal firing rates and patterns in the globus pallidus internus of patients with cervical dystonia differ from those with Parkinson's disease. J Neurophysiol 2007, 98(2):720-729.

64. Coubes P, Roubertie A, Vayssiere N, Hemm S, Echenne B. Treatment of DYT1-generalised dystonia by stimulation of the internal globus pallidus. Lancet 2000, 355(9222):2220-2221.

65. Benabid AL, Koudsie A, Benazzouz A, Vercueil L, Fraix V, Chabardes S et al. Deep brain stimulation of the corpus luysi (subthalamic nucleus) and other targets in Parkinson's disease. Extension to new indications such as dystonia and epilepsy. J Neurol 2001, 248 Suppl 3:III37-III47.

66. Vercueil L, Pollak P, Fraix V, Caputo E, Moro E, Benazzouz A et al. Deep brain stimulation in the treatment of severe dystonia. J Neurol 2001, 248(8):695-700.

67. Kupsch A, Benecke R, Muller J, Trottenberg T, Schneider GH, Poewe W et al. Pallidal deep-brain stimulation in primary generalized or segmental dystonia. N Engl J Med 2006, 355(19):1978-1990.

68. Vidailhet M, Vercueil L, Houeto JL, Krystkowiak P, Lagrange C, Yelnik J et al. Bilateral, pallidal, deepbrain stimulation in primary generalised dystonia: a prospective 3 year follow-up study. Lancet Neurol 2007, 6(3):223-229.

69. Anderson ME, Postupna N, Ruffo M. Effects of high-frequency stimulation in the internal globus pallidus on the activity of thalamic neurons in the awake monkey. J Neurophysiol 2003, 89(2):1150-1160. 
70. Baxter LR, Jr., Phelps ME, Mazziotta JC, Guze BH, Schwartz JM, Selin CE. Local cerebral glucose metabolic rates in obsessive-compulsive disorder. A comparison with rates in unipolar depression and in normal controls. Arch Gen Psychiatry 1987, 44(3):211-218.

71. Swedo SE, Schapiro MB, Grady CL, Cheslow DL, Leonard HL, Kumar A et al. Cerebral glucose metabolism in childhood-onset obsessive-compulsive disorder. Arch Gen Psychiatry 1989, 46(6):518-523.

72. Saxena S, Brody AL, Schwartz JM, Baxter LR. Neuroimaging and frontal-subcortical circuitry in obsessive-compulsive disorder. Br J Psychiatry Suppl 1998,(35):26-37.

73. Guehl D, Benazzouz A, Aouizerate B, Cuny E, Rotge JY, Rougier A et al. Neuronal Correlates of Obsessions in the Caudate Nucleus. Biol Psychiatry 2007.

74. Nuttin B, Cosyns P, Demeulemeester H, Gybels J, Meyerson B. Electrical stimulation in anterior limbs of internal capsules in patients with obsessive-compulsive disorder. Lancet 1999, 354(9189):1526.

75. Van Kuyck K., Gabriels L, Cosyns P, Arckens L, Sturm V, Rasmussen S et al. Behavioural and physiological effects of electrical stimulation in the nucleus accumbens: a review. Acta Neurochir Suppl 2007, 97(Pt 2):375-391.

76. McCracken CB, Grace AA. High-frequency deep brain stimulation of the nucleus accumbens region suppresses neuronal activity and selectively modulates afferent drive in rat orbitofrontal cortex in vivo. J Neurosci 2007, 27(46):12601-12610.

77. Ranck JB. Which elements are excited in electrical stimulation of mammalian central nervous system: a review. Brain Res 1975, 98(3):417-440.

78. Nowak LG, Bullier J. Axons, but not cell bodies, are activated by electrical stimulation in cortical gray matter. I. Evidence from chronaxie measurements. Exp Brain Res 1998, 118(4):477-488.

79. Windels F, Bruet N, Poupard A, Feuerstein C, Bertrand A, Savasta M. Influence of the frequency parameter on extracellular glutamate and gamma-aminobutyric acid in substantia nigra and globus pallidus during electrical stimulation of subthalamic nucleus in rats. J Neurosci Res 2003, 72(2):259-267.

80. Windels F, Carcenac C, Poupard A, Savasta M. Pallidal origin of GABA release within the substantia nigra pars reticulata during high-frequency stimulation of the subthalamic nucleus. J Neurosci 2005, 25(20):5079-5086.

81. Lee KH, Kristic K, van HR, Hitti FL, Blaha C, Harris B et al. High-frequency stimulation of the subthalamic nucleus increases glutamate in the subthalamic nucleus of rats as demonstrated by in vivo enzyme-linked glutamate sensor. Brain Res 2007, 1162:121-129. 
82. Meissner W, Guigoni C, Cirilli L, Garret M, Bioulac BH, Gross CE et al. Impact of chronic subthalamic high-frequency stimulation on metabolic basal ganglia activity: a 2-deoxyglucose uptake and cytochrome oxidase mRNA study in a macaque model of Parkinson's disease. Eur J Neurosci 2007, 25(5):1492-1500.

83. Oueslati A, Sgambato-Faure V, Melon C, Kachidian P, Gubellini P, Amri M et al. High-frequency stimulation of the subthalamic nucleus potentiates L-DOPA-induced neurochemical changes in the striatum in a rat model of Parkinson's disease. J Neurosci 2007, 27(9):2377-2386.

\section{Legends}

\section{Figure 1: STN and the striatal and extrastriatal networks}

STN-DBS preferentially activates axons thus generating spikes that propagate in the antidromic (towards STN, motor cortex, GPe \& PPN somas) and orthodromic (towards GPe, GPi, SNr, SNc, PPN) directions. Passing fibers can also be activated. As a result, all the nuclei of the extrastriatal network and motor cortical areas are directly affected by STN-DBS. The striatal network is indirectly affected via the modulation of dopaminergic neurons of the SNc. When antidromic spikes propagate back to a structure, they may invade somas and axon collaterals and thus activate other projection neurons and local interneurons when they exist (insets show simplified cortical ${ }^{76}$ and GPe networks).

\section{Figure 2 DBS-driven antidromic spikes}

Antidromic responses in (A) STN neurons in response to STN-HFS (note IS spike at $t=120$ ms, middle and IS-SD break, right) (Garcia et al, unpublished figure) (B) Motor cortical neurons in response to STN-DBS (arrow head indicates collision, right ${ }^{32}$, (C) GPe neurons in response to STN-HFS (Ammari et al, unpublished data) (D) SNr neurons in response to STNDBS (note collision, bottom trace, right) ${ }^{36}$, (E) Vop thalamic neurons in response to GPi-DBS (post-stimulus raster plot, top; histogram, bottom; antidromic spikes, right) ${ }^{30}$. 


\section{Figure 3: DBS-driven orthodromic responses}

Orthodromic responses of (A) GPi neurons in response to STN-DBS (complex sequence of

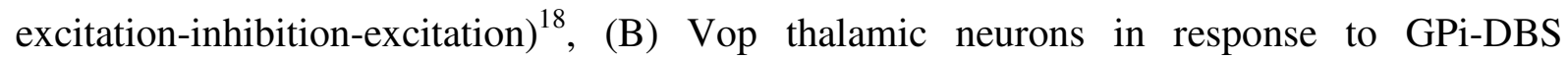
(antidromic activation followed by a complex sequence of excitation-inhibition-excitation, post stimulus rater, top and histogram, bottom $)^{30}$. 


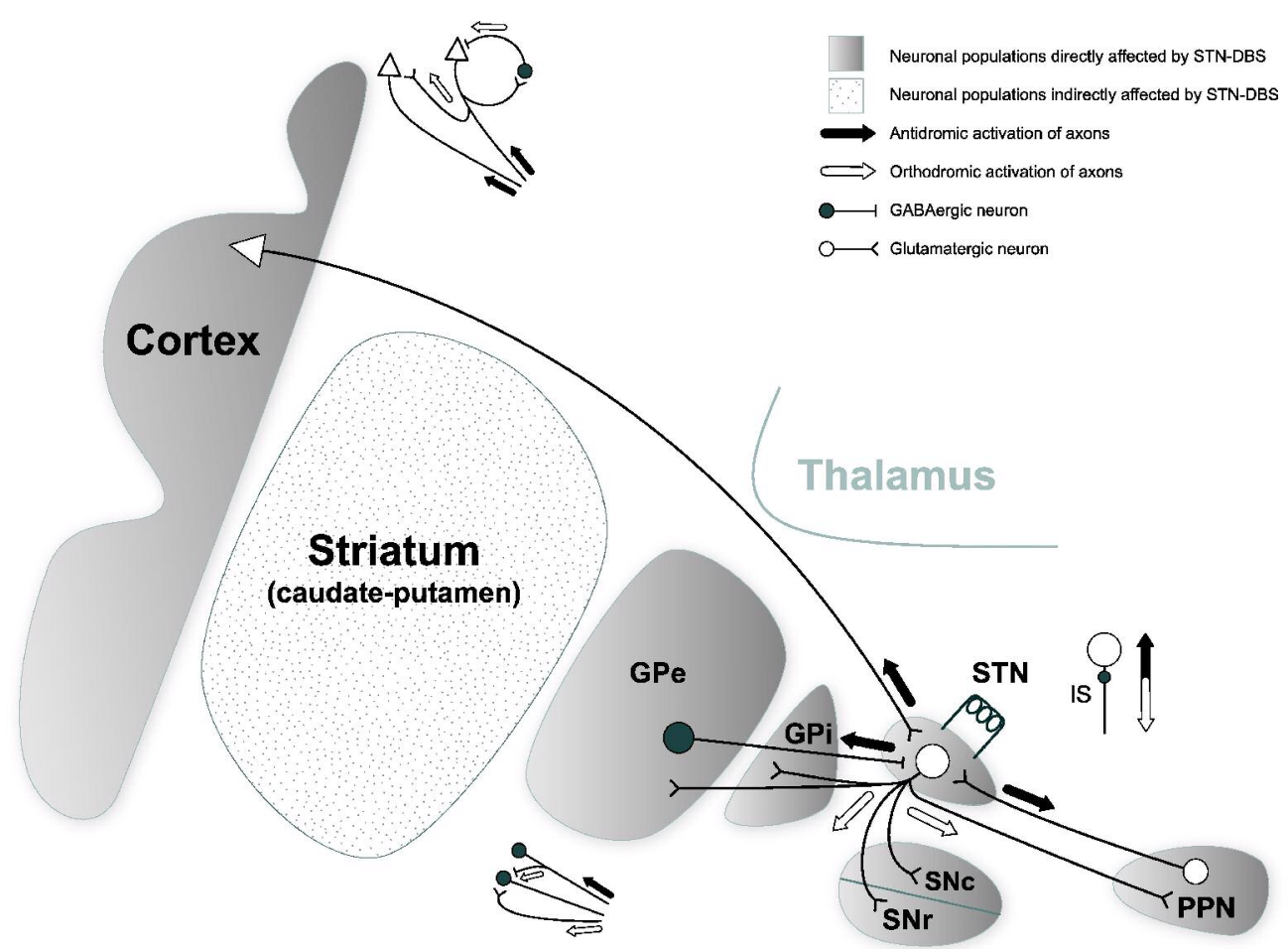

Figure 1: STN and the striatal and extrastriatal networks STN-DBS preferentially activates axons thus generating spikes that propagate in the antidromic (towards STN, motor cortex, GPe \& PPN somas) and orthodromic (towards GPe, GPi, SNr, SNc, PPN) directions. Passing fibers can also be activated. As a result, all the nuclei of the extrastriatal network and motor cortical areas are directly affected by STN-DBS. The striatal network is indirectly affected via the modulation of dopaminergic neurons of the SNc. When antidromic spikes propagate back to a structure, they may invade somas and axon collaterals and thus activate other projection neurons and local interneurons when they exist (insets show simplified cortical ${ }^{76}$ and GPe networks). $192 \times 141 \mathrm{~mm}(600 \times 600$ DPI $)$ 

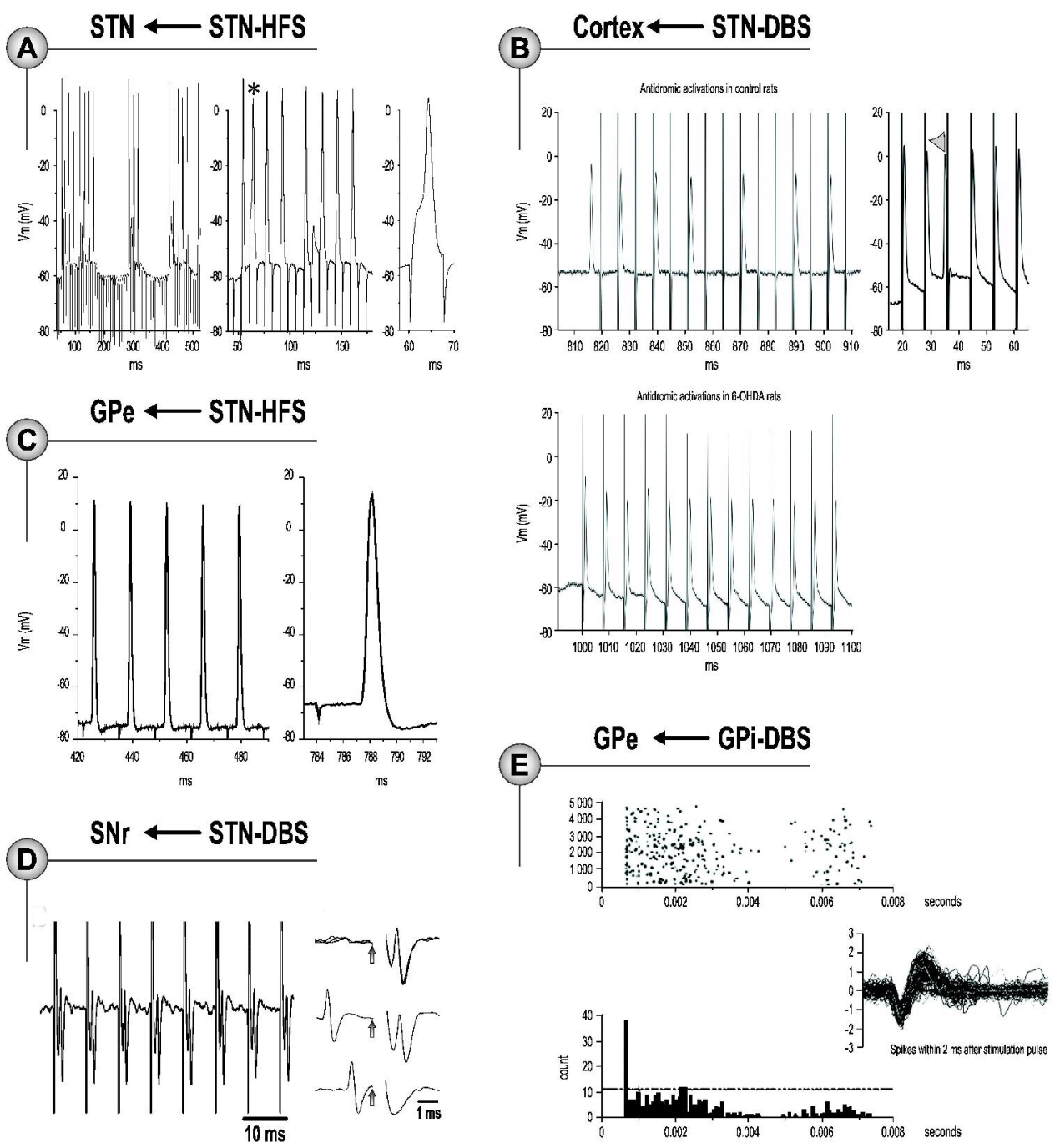

Figure 2 DBS-driven antidromic spikes Antidromic responses in (A) STN neurons in response to STN-HFS (note IS spike at $t=120 \mathrm{~ms}$, middle and IS-SD break, right) (Garcia et al, unpublished figure) (B) Motor cortical neurons in response to STN-DBS (arrow head indicates collision, right) ${ }^{32}$, (C) GPe neurons in response to STN-HFS (Ammari et al, unpublished data) (D) SNr neurons in response to STN-DBS (note collision, bottom trace, right) ${ }^{36}$, (E) Vop thalamic neurons in response to GPi-DBS (post-stimulus raster plot, top; histogram, bottom; antidromic spikes, right) ${ }^{30}$. $205 \times 220 \mathrm{~mm}(600 \times 600 \mathrm{DPI})$ 

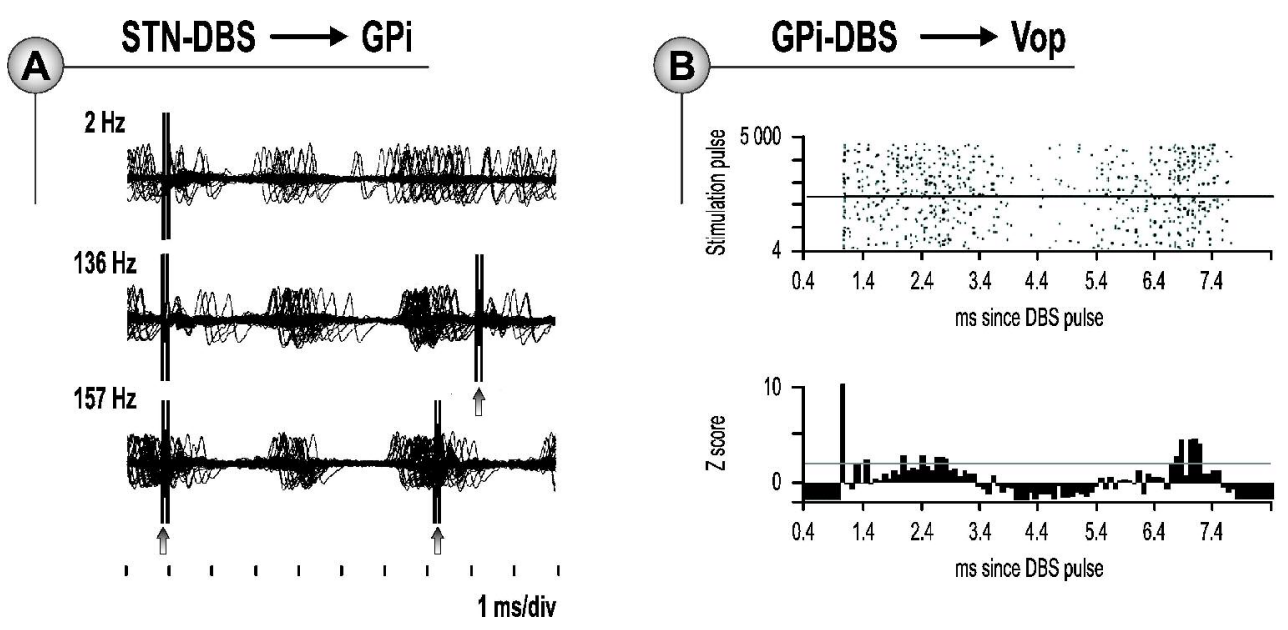

Figure 3: DBS-driven orthodromic responses Orthodromic responses of (A) GPi neurons in response to STN-DBS (complex sequence of excitation-inhibition-excitation) ${ }^{18}$, (B) Vop thalamic neurons in response to GPi-DBS (antidromic activation followed by a complex sequence of excitation-inhibition-excitation, post stimulus rater, top and histogram, bottom $)^{30}$.

$181 \times 83 \mathrm{~mm}(600 \times 600 \mathrm{DPI})$ 


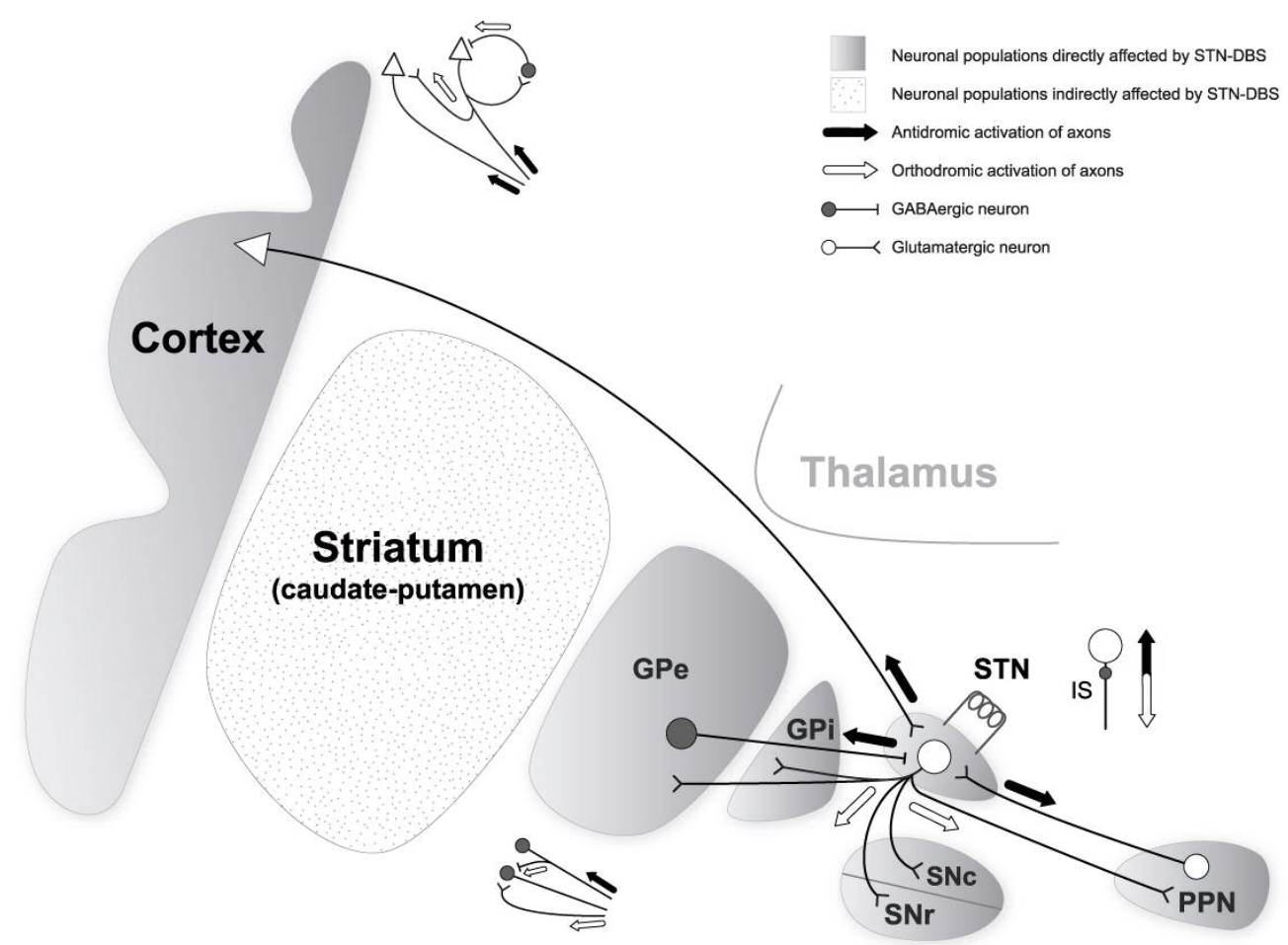

Figure 1: STN and the striatal and extrastriatal networks STN-DBS preferentially activates axons thus generating spikes that propagate in the antidromic (towards STN, motor cortex, GPe \& PPN somas) and orthodromic (towards GPe, GPi, SNr, SNc, PPN) directions. Passing fibers can also be activated. As a result, all the nuclei of the extrastriatal network and motor cortical areas are directly affected by STN-DBS. The striatal network is indirectly affected via the modulation of dopaminergic neurons of the SNc. When antidromic spikes propagate back to a structure, they may invade somas and axon collaterals and thus activate other projection neurons and local interneurons when they exist (insets show simplified cortical ${ }^{76}$ and GPe networks). $192 \times 141 \mathrm{~mm}(150 \times 150 \mathrm{DPI})$ 

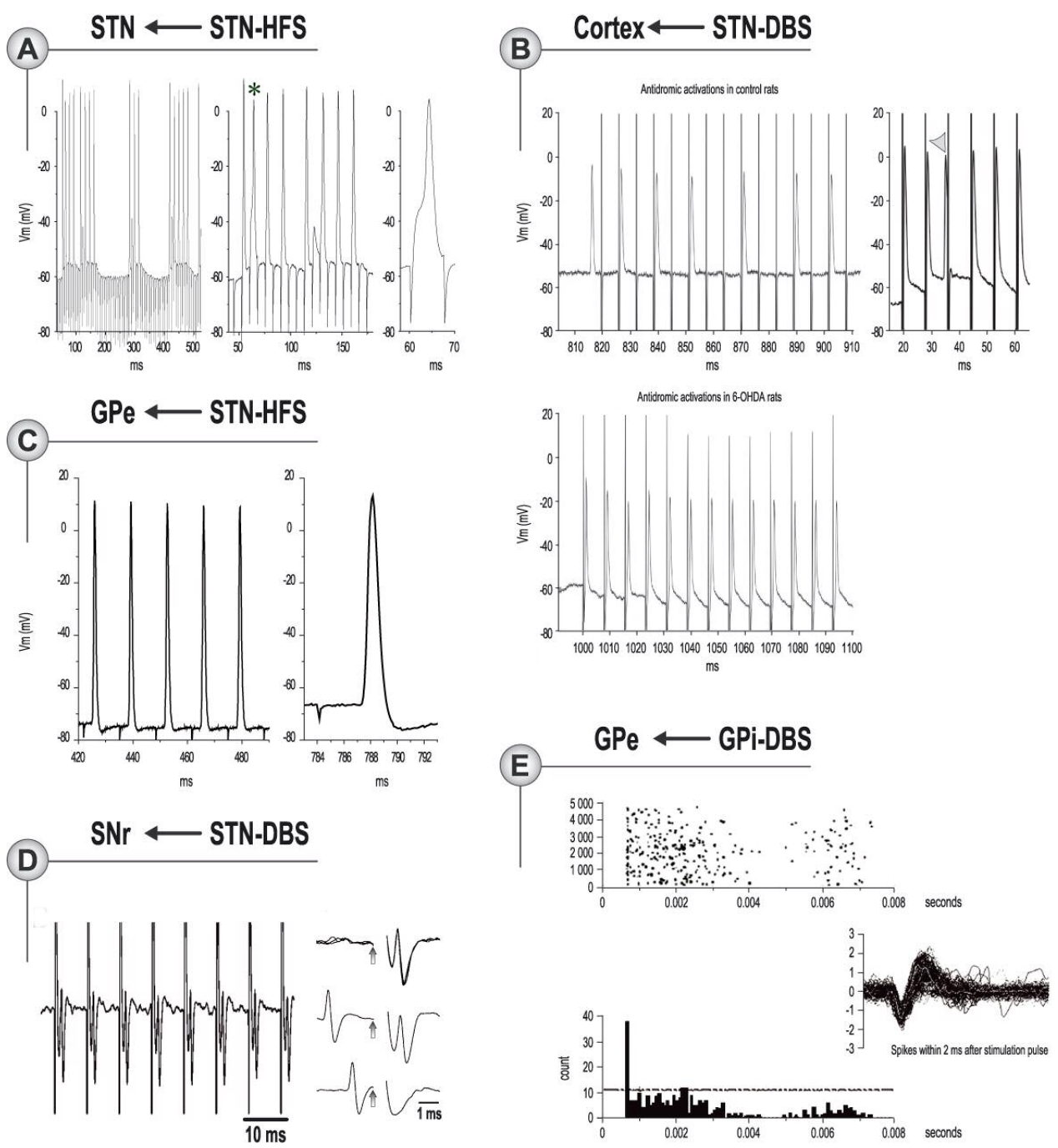

Figure 2 DBS-driven antidromic spikes Antidromic responses in (A) STN neurons in response to STN-HFS (note IS spike at $t=120 \mathrm{~ms}$, middle and IS-SD break, right) (Garcia et al, unpublished figure) (B) Motor cortical neurons in response to STN-DBS (arrow head indicates collision, right) ${ }^{32}$, (C) GPe neurons in response to STN-HFS (Ammari et al, unpublished data) (D) SNr neurons in response to STN-DBS (note collision, bottom trace, right) ${ }^{36}$, (E) Vop thalamic neurons in response to GPi-DBS (post-stimulus raster plot, top; histogram, bottom; antidromic spikes, right) ${ }^{30}$. $205 \times 220 \mathrm{~mm}(150 \times 150 \mathrm{DPI})$ 

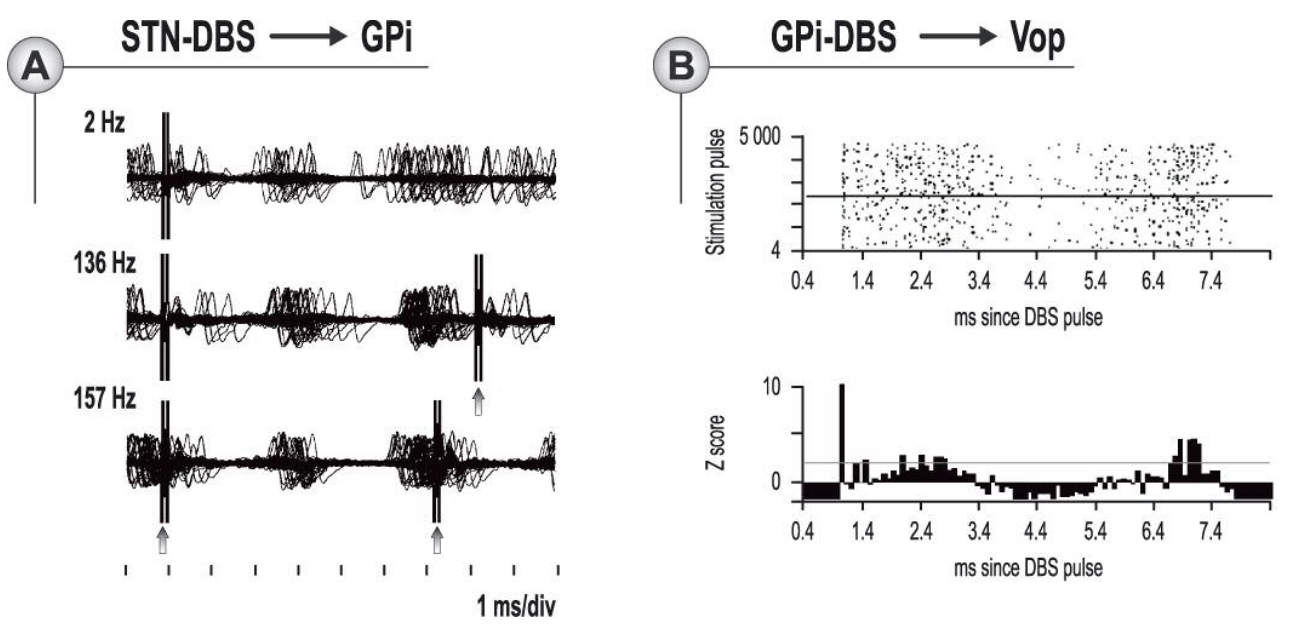

Figure 3: DBS-driven orthodromic responses Orthodromic responses of (A) GPi neurons in response to STN-DBS (complex sequence of excitation-inhibition-excitation) ${ }^{18}$, (B) Vop thalamic neurons in response to GPi-DBS (antidromic activation followed by a complex sequence of excitation-inhibition-excitation, post stimulus rater, top and histogram, bottom $)^{30}$.

$182 \times 83 \mathrm{~mm}(150 \times 150 \mathrm{DPI})$ 